\title{
Digital Preservation Practices among Midwestern Four-year Public Colleges and Universities
}

\section{By Matt Gorzalski}

\begin{abstract}
This article is the result of a study to survey the landscape of digital preservation practices and infrastructure at midwestern four-year public colleges and universities. It summarizes the staffing, tools, policy, and procedural characteristics of the survey population, compares these results to previous studies, and questions if a model for a successful program has emerged. The article concludes by arguing that instead of measuring digital preservation program development to existing ideal models, resource-strapped archives will better assess progress using a matrix linking reasonably achievable infrastructure and workflows with corresponding, categorized levels of financial, technical, and human resources.
\end{abstract}

\section{Introduction}

Much has changed since Lisl Zach and Marcia Frank Peri's 2005-2009 study of college and university electronic records management programs found that "no uniform solution appears to be available for developing and implementing a successful ERM [electronic records management] program." ${ }^{1}$ Popular open source tools such as BitCurator and Archivematica and vendor services such as Preservica and DuraCloud now allow archivists to automate the acquisition, processing, preservation, and accessibility of born-digital and digitized records. Continuing education opportunities have also emerged, notably the Society of American Archivists' Digital Archives Specialist program, which have strengthened archivists' practical skills and knowledge about digital records management.

Despite these advances, many archivists remain challenged by dwindling budgets, lack of institutional support, and limited technical knowledge, all of which hinder the development of digital records management programs at their institutions. This article is the result of a study to survey the landscape of digital preservation practices and infrastructure at midwestern four-year public colleges and universities. It was conceived during the author's ongoing efforts to develop such a program at Southern Illinois University Carbondale (SIUC) during the 2015-2017 state budget impasse. The article summarizes the staffing, tools, policy, and procedural characteristics of the survey population, compares these results to previous studies, and determines if a model for a successful program has emerged since Zach and Peri's study.

\section{Literature Review}

The literature on the challenges and strategies for archival management of electronic or 
born-digital records is voluminous, multidisciplinary, and often multi-institutional. It is difficult both to describe the universe of literature on this topic and to isolate research on these activities occurring solely at colleges and universities. This literature review frames the author's study by briefly highlighting significant research initiatives and selected college- and university-specific case studies, followed by a review of previous surveys on electronic or born-digital records practices and infrastructure.

The arrival of personal computers in the $1970 \mathrm{~s}^{2}$ brought electronic records issues to the forefront of archival discussion. Since the 1980s, the National Archives and Records Administration, granting agencies, state agencies, and archivists have held conferences, published reports, and engaged in research aimed at understanding the complexities of electronic records management and preservation. ${ }^{3}$ The National Historical Publications and Records Commission (NHPRC) developed a seminal electronic records research agenda that funded or influenced many projects including those at the Minnesota Historical Society, the University of Pittsburgh, and the University of Michigan. ${ }^{4}$ Archivists at the University of British Columbia also used NHPRC funding for InterPARES, a multiphase project that tested diplomatics in digital environments and developed requirements for preserving authentic electronic records. ${ }^{5}$ The results of these projects largely established the foundational knowledge necessary for developing and refining digital preservation best practices and tools.

Electronic records challenge all facets of archival work, and the literature reflects this. Broadly, archivists have explored issues concerning the records life cycle versus continuum models, preservation of electronic media and file format versus file content, appraisal and custody, arrangement and description, authenticity, advocacy and program building, access systems, and education. ${ }^{6}$ Several case studies report the activities at specific colleges and universities. Archivists at Indiana University (IU) tested the Pittsburgh Project's functional requirements for evidence in recordkeeping on IU information systems, a project that provides guidance on functional analysis of electronic recordkeeping systems. ${ }^{7}$ Leaders of the Preserving Digital Objects with Restricted Resources (POWRR) project offered strategies and tool analyses for archivists challenged by limited financial, technological, and institutional support. ${ }^{8}$ Others in higher education have described approaches for managing born-digital institutional and personal records, websites, research data, and e-mail, many of which are featured in the Society of American Archivists' Campus Case Studies series. ${ }^{9}$ The progress made in these areas of theory and practice has shaped a consensus of best practices for electronic records management. ${ }^{10}$ This and the development of software and continuing education courses have empowered archivists in establishing born-digital preservation programs.

Several studies have examined the overall state of digital preservation programs. The 2006 A*CENSUS and 2010 Taking Our Pulse surveys revealed similarities in the percentages of respondents identifying electronic records as the top (39\%) or second greatest (38\%) challenge facing the profession, with $38.5 \%$ and $35 \%$ reporting active work with electronic records, respectively. ${ }^{11}$ A 1998 survey of Research Libraries Group members found that while two-thirds (66\%) assumed responsibility for preserving 
digital materials, shortfalls existed in policy development and staff expertise, as well as concerns about the ad hoc nature of preservation strategies. ${ }^{12}$ The absence of policies and procedures is a recurring theme in nearly all studies. Surveys in 2002 of academic libraries and 2013 of Association of Research Libraries (ARL) members on digital image collections found that only $6 \%$ and $37 \%$, respectively, of respondents had preservation policies or procedures for digital materials. ${ }^{13}$ A 2002 survey of university archives and records programs identified several familiar obstacles: lack of policies and procedures and miniscule influence in their institutional information infrastructures. ${ }^{14} \mathrm{~A}$ few years later, Zach and Peri's study of North American college and university archives and records management programs found no increase in the percentage (49\%) of reported electronic records management programs between their 2005 and 2009 data sets. ${ }^{15}$ More recent studies provide a comprehensive picture of ARL members' digital preservation programs. SPEC Kit 325 noted that $80 \%$ of respondents preserve digital content, $90 \%$ engage in local-level preservation activities, and $44 \%$ had begun policy planning. ${ }^{16}$ SPEC Kit 329 reported $92 \%$ of respondents "already collect born-digital content" and that these institutions had made significant progress toward digital preservation policies and procedures. ${ }^{17}$ These SPEC Kits and the Zach and Peri study will be revisited when discussing the results of this article's survey.

Several additional surveys have targeted specific aspects of digital preservation. Michèle V. Cloonan and Shelby Sanett's survey concluded that common preservation strategies failed to meet the conceptual requirements for authentic electronic records and discussed the dearth of digital preservation cost models. ${ }^{18}$ A PREMIS study noted emerging trends in the use of preservation metadata schemes and types of metadata within digital preservation repositories. ${ }^{19}$ A related 2008 study of institutional repositories found that "IRs have not become the equivalent of trusted digital repositories," despite preservation being a recognized significant component of IRs. ${ }^{20}$ Susan E. Davis found that "collecting repositories" generally acquire digital records from external donors on an ad hoc as opposed to a policy-driven basis, a consequence of archivists being overlooked during institutional policymaking. ${ }^{21}$ The National Digital Stewardship Alliance published studies on its members' digital storage infrastructures, revealing encouraging progress despite minimal adoption of trusted digital repository standards. ${ }^{22}$ Other surveys have focused on data curation, web archiving, and staffing for digital preservation. ${ }^{23}$ When considering the case studies together with the findings of these surveys, they demonstrate overall increasing sophistication in the development of digital preservation policies and procedures. However, the degree of progress is not universal among archives of all sizes and resource levels, and every digital preservation program includes areas of weakness that need improvement.

\section{Study Scope and Methodology}

This study is a survey of digital preservation practices and infrastructure at midwestern four-year public colleges and universities. The author chose this population because many midwestern states face similar demographic and economic challenges. As the Midwest loses population to the West and the South, the resulting decline in workforce 
slows economic activity, reduces state government tax revenue, and increases financial pressure on public institutions that rely on state money. ${ }^{24}$ Illinois led the nation in population loss in 2016, and its universities were hard hit by the 2015-2017 budget impasse, suffering an aggregate $61 \%$ budget cut in 2015-2016 alone. ${ }^{25}$ When compared to the last budget in FY15, SIUC endured a 71\% reduction in state appropriations for FY16, followed by another $10 \%$ in FY17. ${ }^{26}$ Higher education in other midwestern states has faced severe budget challenges in recent years. ${ }^{27}$

While attempting to develop a digital preservation program in this environment, the author became interested in how similar programs fared at other midwestern institutions. The author distributed a 33-question survey to 129 archivists and librarians employed at four-year public colleges and universities in Midwest Archives Conference (MAC) states. Limiting the study population to institutions in the MAC region facilitated a workable data set. The survey was divided into seven sections, the results of which are discussed below: "Background Information"; "Staffing; Policies and Procedures"; "Acquisition, Ingest, Preservation, and Access"; "Digital Storage”; "Sustainability"; and "Conclusion."

The author identified the colleges and universities using lists by state found on Wikipedia. ${ }^{28} \mathrm{He}$ then consulted staff rosters to identify the appropriate individual to complete the survey for each institution, based on department (archives, preservation, and special collections) and job title. The targeted job title was electronic records archivist or a similar title such as preservation librarian, digital initiatives librarian, digital archivist, or university archivist. The author made presurvey contacts with a number of individuals to verify that they were the people most appropriate to complete the survey. This resulted in a few changes to the original recipient list. The survey was open for a threeweek period from September 6 to 27, 2017.

\section{Survey Results-The Big Picture}

The survey returned 44 completed and 10 partially completed responses for a total of 54 responses and a $42 \%$ response rate. Fifteen of the fifty-four respondents $(28 \%)$ represented ARL members. Figure 1 depicts the geographical distribution of respondents. Respondents were asked to indicate the size of their institutions based on current student enrollment; the majority represented midsized or large colleges and universities (see figure 2). ${ }^{29}$

Most respondents $(n=46$, or $85 \%)$ reported that they are at least planning for a borndigital records preservation program. More specifically, when presented five defined categories and asked to choose the category that best described the developmental stage of their program, the results were as follows: 8 (15\%) selected "No Current Efforts"; 16 (30\%) selected "Planning Stage"; 20 (37\%) selected "Early Implementation"; 10 (19\%) selected "Refining and Maturing"; and none selected "Full Implementation." When these categories are considered in the context of institutional size based on current student enrollment, the results indicate that larger institutions with presumably greater 


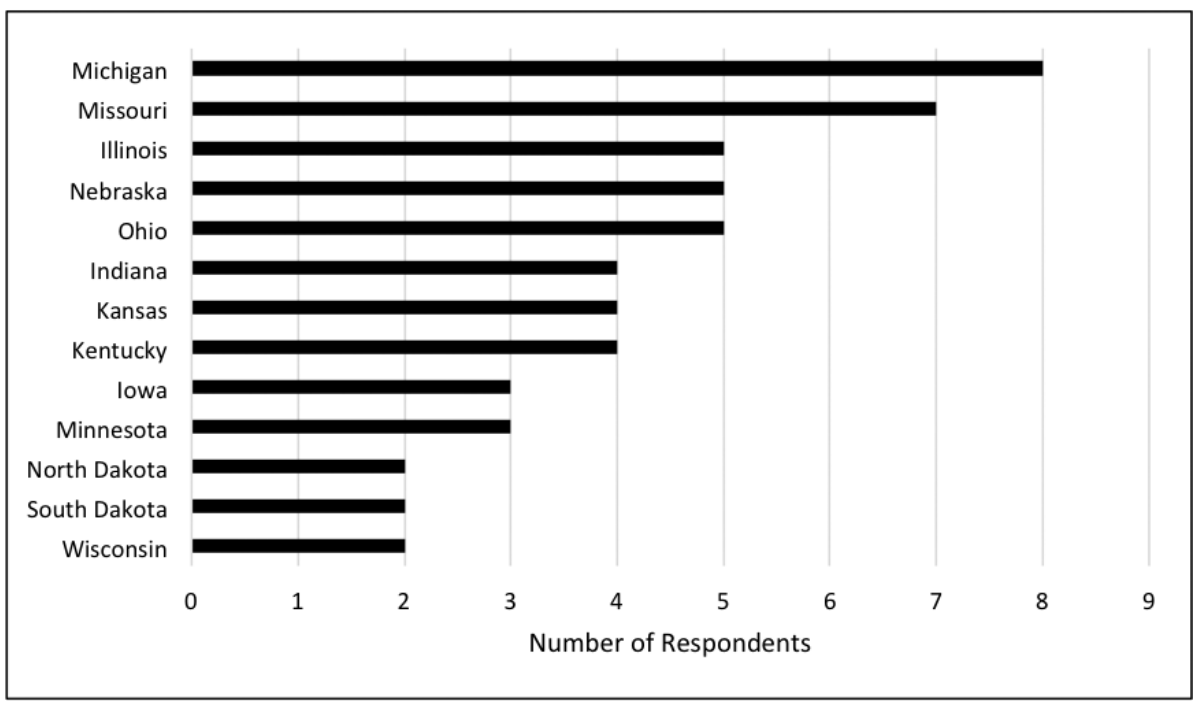

Figure 1: Geographic distribution of responding colleges and universities

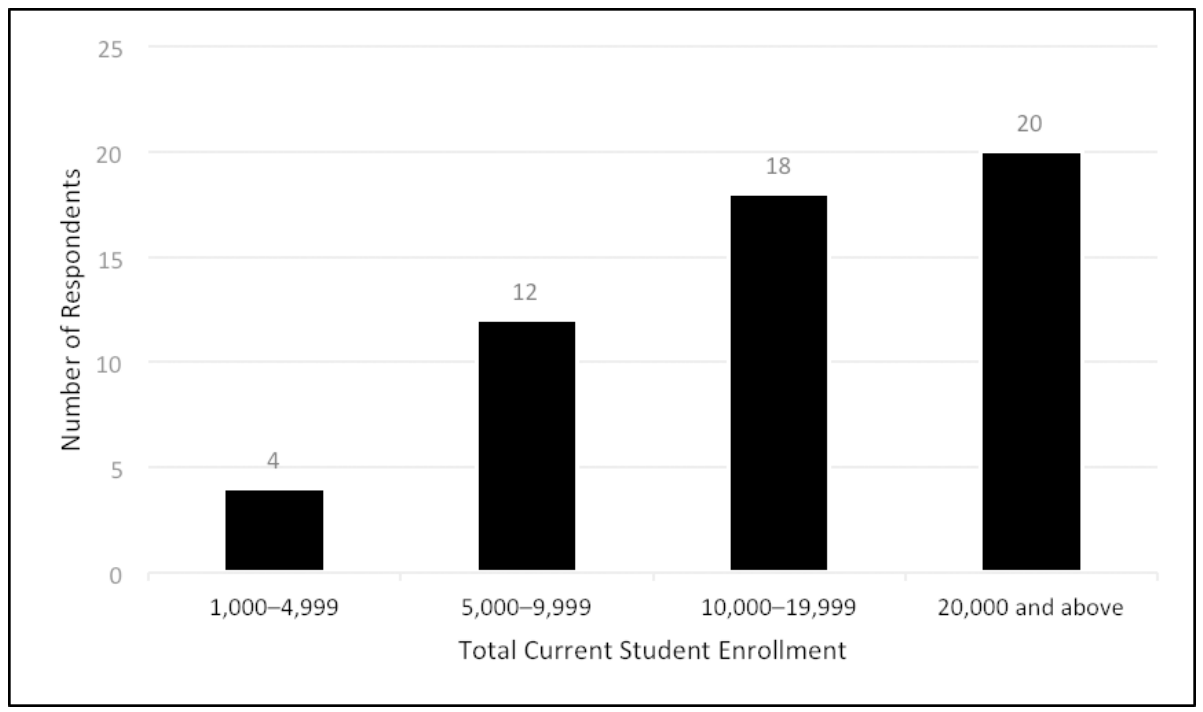

Figure 2: Size of responding colleges and universities based on current enrollment

staffing and financial and technical resources operate more mature programs (see figure 3). Institutions with more than 20,000 students comprise $80 \%$ of respondents among the "Refining and Maturing" developmental stage. Institutions under 10,000 students steadily decrease in percentage of respondents as program developmental stages progress. Midsized institutions (10,000-19,999 students) span all developmental stages, but as expected, represent the largest percentage of early implementers. 


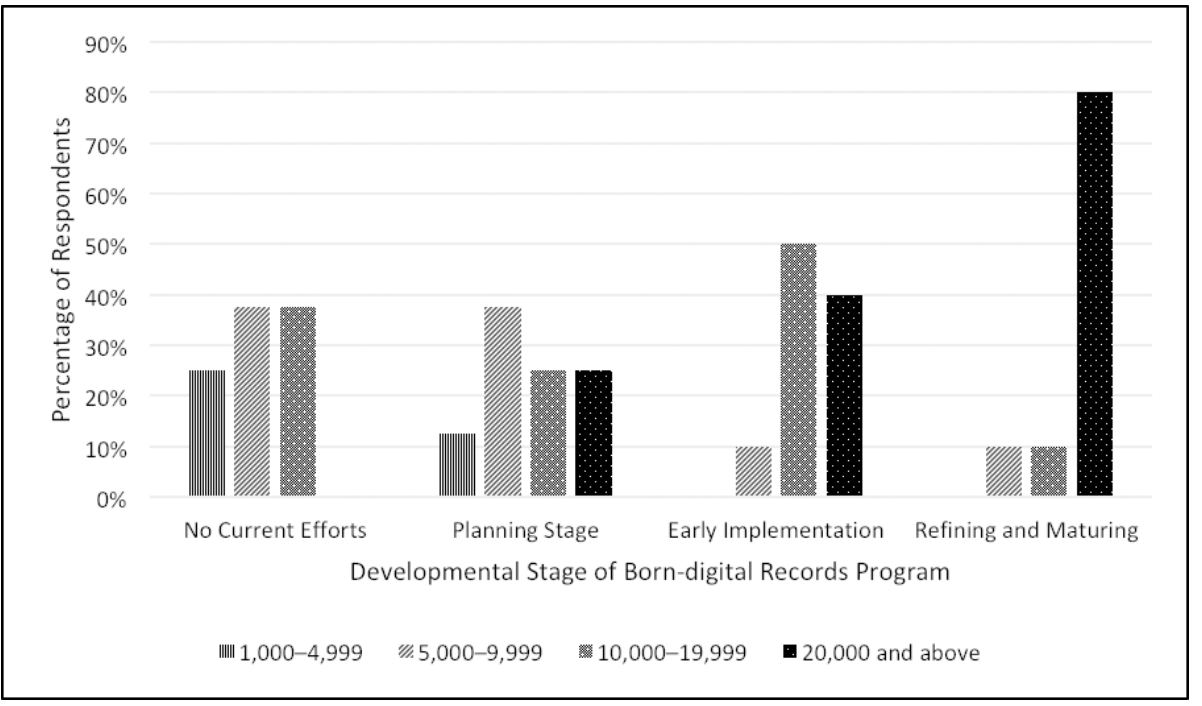

Figure 3: Relationship between institutional size in student enrollment and developmental stage of borndigital records preservation program

It is encouraging that $85 \%$ of respondents are at least planning for a born-digital preservation program, of which $65 \%$ (30 of the 46 respondents) have begun preservation activities. These numbers are similar to those in studies of ARL members. SPEC Kit 325 reported $80 \%$ of respondents were "actively investing in the preservation" of digital content and 16\% had begun planning, and SPEC Kit 329 noted that $92 \%$ "collect and manage born-digital materials" and $8 \%$ planned to. Archivists appear increasingly confident in managing born-digital records since 2010, when Zach and Peri found only $49 \%$ "reported having a formal ERM program either in place or in the planning stages." 30

\section{Staffing}

Fifty respondents answered the question "Does your repository/institution employ an electronic or digital records archivist with the primary responsibility of acquiring, preserving, and providing access to born-digital records?" Of these, $84 \%(n=42)$ responded "no" and 16\% $(n=8)$ responded "yes." Contrary to expectations, larger institutions were not more likely to have an archivist primarily responsible for born-digital records. Of the 8 "yes" responses, 6 represent the 20,000 and above and 2 represent the 1,000-4,999 student enrollment categories. However, the data do show an increasing likelihood of employing a dedicated electronic/digital records archivist as programs mature (see figure 4). Zach and Peri similarly observed a positive relationship between employing a dedicated records manager and the presence of, or plans for, an electronic records management program. ${ }^{31}$ 


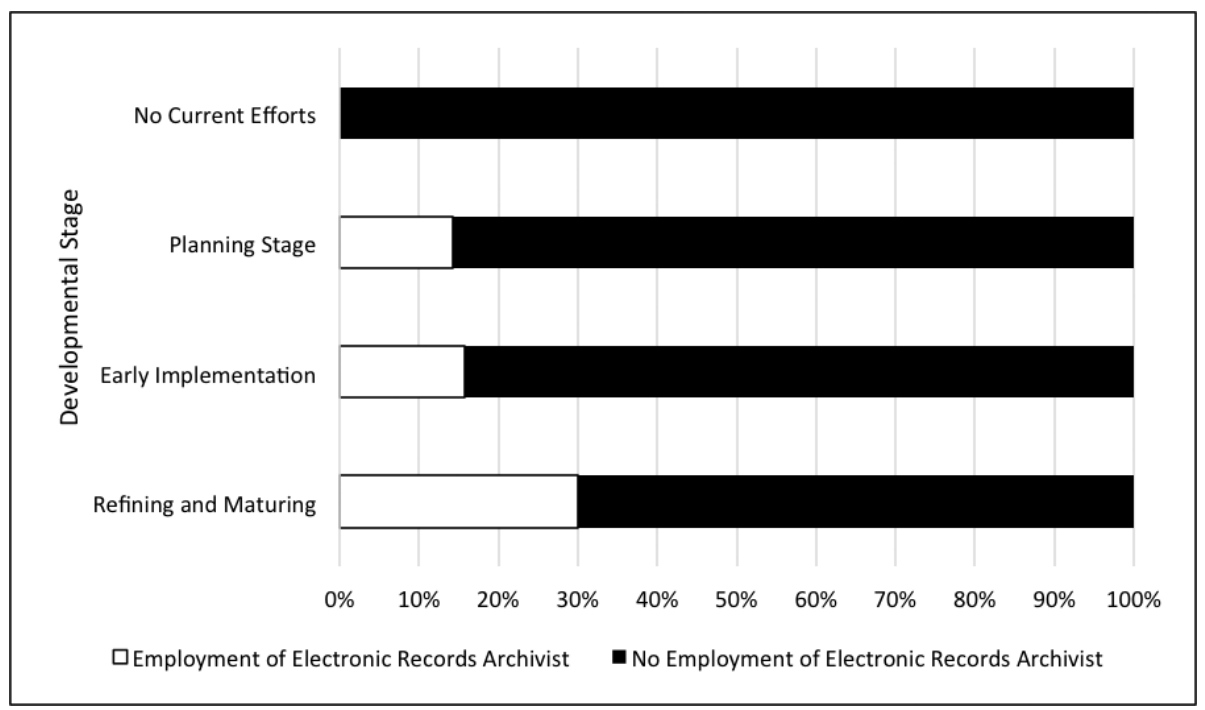

Figure 4: Relationship between developmental stage of born-digital records program and employment of a dedicated electronic records archivist

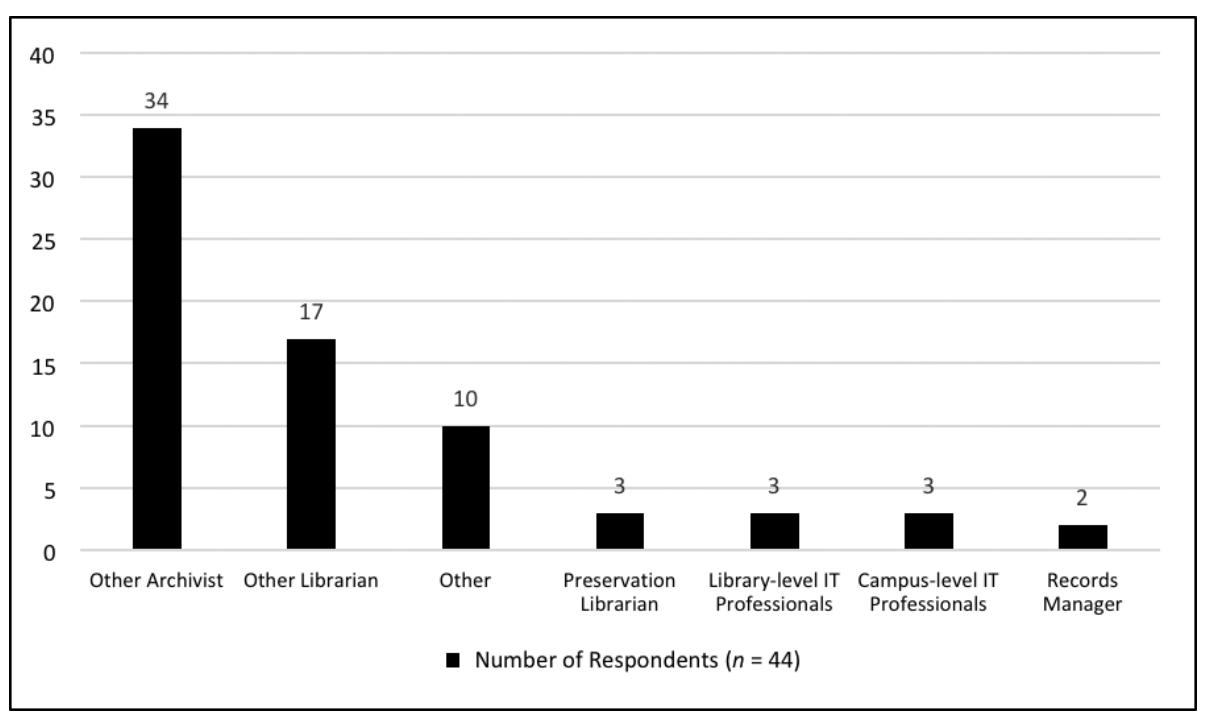

Figure 5: Positions responsible for born-digital records at institutions not employing a dedicated electronic/digital records archivist

Figure 5 shows the positions responsible for managing born-digital records at 44 institutions not employing an archivist for this purpose. This survey question permitted multiple selections. "Other Archivist" included options such as university archivist or collections archivist, and "Other Librarian" included options such as digital initiatives librarian or digital repository librarian, among others. Those selecting "Other (please 
specify)" often described collaborations between archivists, librarians, preservationists, IT professionals, and even paraprofessional staff. It is expected, however, that dedicated electronic records archivists also collaborate with stakeholders at their institutions.

The comparison studies confirm the variety of positions involved in born-digital records preservation. Zach and Peri (2010) noted that appraisal and acquisition decisions were made by archivists, campus departments, legal counsel, risk managers, and financial administrators in institutions without records managers. For these same functions, SPEC Kit 325 listed digital initiatives librarians, collections managers, special collections librarians and archivists, content providers, and administrators. Likewise, SPEC Kit 329 mentioned staff involved with digitization, digital curation, campus IT, special collections and archives, preservation, administration, and consortia as participants in digital records management. ${ }^{32}$

Table 1: Staffing Statistics of This Survey and SPEC Kits 325 and 329

\begin{tabular}{|c|c|c|c|c|c|}
\cline { 2 - 6 } \multicolumn{1}{c|}{} & Minimum & Maximum & Mean & Median & Std. Dev. \\
\hline FTE & 0 & 15 & 1.96 & 1 & 2.75 \\
\hline Individuals & 0 & 16 & 2.94 & 2 & 3.15 \\
\hline
\end{tabular}

\begin{tabular}{|c|c|c|c|c|c|}
\hline SPEC Kit 325 & Minimum & Maximum & Mean & Median & Std. Dev. \\
\hline FTE & 0.20 & 100 & 4.71 & 2 & 14.62 \\
\hline Individuals & 1.00 & 100 & 8.30 & 5 & 14.67 \\
\hline
\end{tabular}

\begin{tabular}{|c|c|c|c|c|c|}
\hline SPEC Kit 329 & Minimum & Maximum & Mean & Median & Std. Dev. \\
\hline FTE & 0.10 & 60 & 4.73 & 2 & 9.25 \\
\hline Individuals & 1 & 48 & 6.64 & 5.50 & 7.75 \\
\hline
\end{tabular}

Respondents were asked to state the number of staff responsible for the acquisition, appraisal, preservation, and access to born-digital records in both full-time equivalent (FTE) and individual employees. Some responses were discarded in cases where the question was not answered correctly. Thirty-six of the forty-seven FTE responses and 36 of the 46 "individuals" responses were usable. ${ }^{33}$ Table 1 compares the statistical results from this survey to those of SPEC Kits 325 and 329, which asked the same question. ${ }^{34}$ Predictably, SPEC Kits 325 and 329 report more FTEs and individuals given their exclusive focus on ARL members. The present survey found that respondents with the largest number of FTEs at 3 or more are all ARL members $(n=5)$ with student enrollment of at least 20,000.

Twenty-one institutions (58\%) reported having 1 to 3 FTEs responsible for managing born-digital records. Ten respondents (28\%) have less than 1 FTE, and, as noted, $5(14 \%)$ have more than 3 . A majority of respondents (64\%) reported having 2 or more individuals $(n=23)$, and $36 \%$ reported 1 or 0 individuals $(n=13)$ managing born-digital 
records. The data did not reveal a statistically significant relationship between enrollment size and FTE and individual staffing numbers. The fact that, on average, the number of individuals is greater than the number of FTEs reflects the need to collaborate in managing born-digital records. As one respondent noted, “. . . we have 5 people who contribute in some way to the effort, but none of us spends the majority of our time on digital acquisition, appraisal, preservation, and access to born-digital records." Of all usable responses, 9 reported a 1:1 ration of FTEs and individuals. These findings reflect little change since 2011 when SPEC Kit 325 that found 64\% of respondents had 1 to 3 FTEs, and that "digital preservation responsibilities are divided among two or more library staff and only rarely is an entire FTE embodied in one individual." ${ }^{35}$

A majority of respondents (72\%) felt that current staffing levels are insufficient to support born-digital records preservation at their institutions $(n=36)$; only $8 \%(n=4)$ felt adequately staffed. Ten respondents (20\%) were uncertain, as most $(n=7)$ are in the early phases of planning a digital preservation program. The survey did not identify an optimal staffing level. Instead, the responses confirm the assumption that the sophistication of archival programs and related staffing needs are relative and situational. The 4 institutions that felt sufficiently staffed, 2 of which are ARL members, reported 3, 5, and 15 FTEs, ${ }^{36}$ but 3 institutions with 5, 5, and 7 FTEs, all ARL members, felt uncertain or understaffed. That only 1 of these 7 enrolls fewer than 10,000 students suggests that even midsized to large institutions with presumably more resources can feel insecure about the adequacy of their digital preservation infrastructure. As one stated, "Out of the 7 individuals who work with born-digital materials, we spend between $3-50 \%$ of our time working with these materials. Even with this pretty high number, we have so many digital materials ... that we could be doing so much more to preserve and provide access to this content if we had additional staff."

Certainly, ARL members are better positioned to address staffing needs for managing born-digital records. SPEC Kit 325 reported that $67 \%$ of respondents had added staff for this purpose and 61\% expected future increases. Likewise, SPEC Kit 329 noted that $46 \%$ of respondents had created or planned to create new staff positions. ${ }^{37}$ Small to midsized public colleges and universities often struggle to fill existing positions let alone add new ones.

\section{Policies and Procedures}

Only 26\% $(n=12)$ of 47 respondents have created deeds of gifts, records transfer forms, purchase agreements, or other types of accessioning documents specifically for borndigital records. The remaining $57 \%$ do not $(n=27)$, while $6 \%$ were unsure $(n=3)$. The 5 respondents (11\%) who selected "other (please specify)" were either drafting language on born-digital materials to incorporate into existing accessioning records, following a records retention schedule, or had no current plans to develop such documents. The question's wording makes it difficult to graph the data with the comparison studies. However, the percentages are comparable to SPEC Kit 329, which reported that 29\% 
had and $71 \%$ had not developed language for gift/purchasing agreements specific to born-digital records. ${ }^{38}$

Figure 6 shows the percentages of respondents using policies and/or procedures for the listed born-digital records management activities. It combines responses from two separate questions for which the number of respondents is noted by the $n$ value. Overall, $57 \%$ and $65 \%$ of respondents have written policies and procedures, respectively, for at least some of the listed activities.

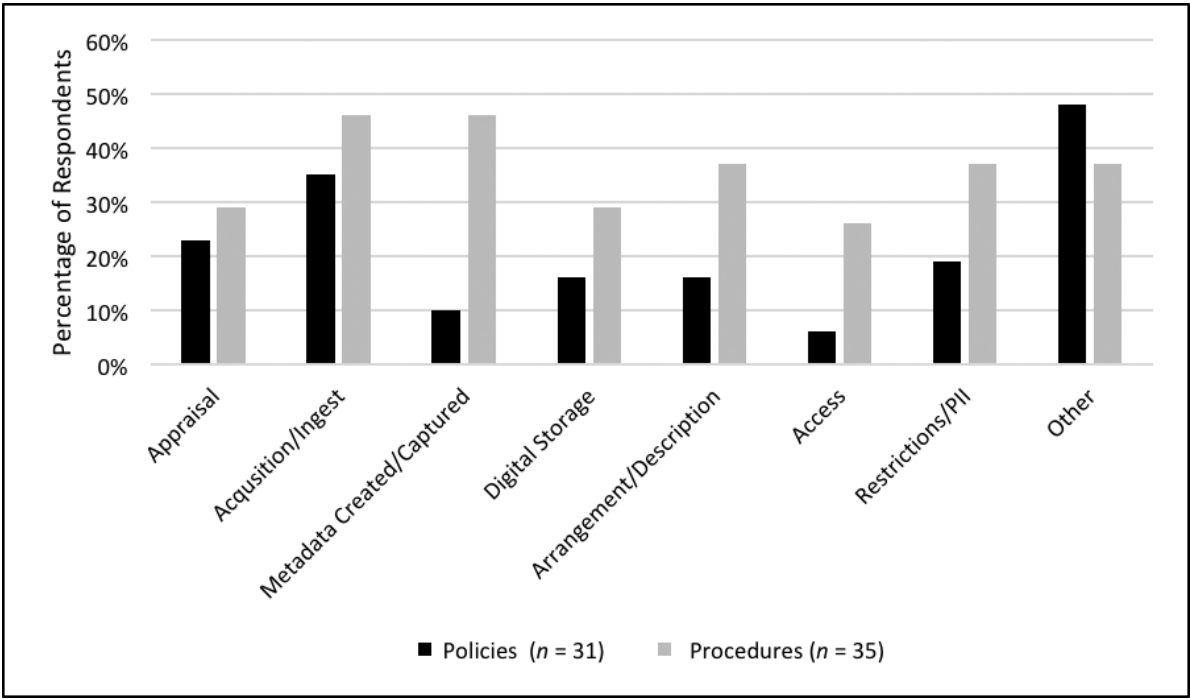

Figure 6: Use of written policies and procedures for born-digital records management activities among MAC institutions

Given the analytical nature of and the need for consistency in appraisal and acquisition decisions, these logically represent the areas for which the largest percentages of respondents have policies. Ingest activities are both procedural and include policy aspects such as limiting preserved file format types. It is surprising that more respondents do not have policies on restrictions and personally identifiable information (PII). Because this question permitted multiple selections, respondents may not have chosen this category if such language is included in appraisal and acquisition policies. Of those selecting "other" who provided usable responses, 4 responded with "none"; 5 used legacy policies that may or may not include language specific to born-digital records; 3 noted specific internal policies that did not fall clearly within the other categories; and 2 were in the process of drafting policies. Percentages for written procedures are more evenly distributed, likely because they have long been used for consistent treatment of collections, which is crucial for managing born-digital records. Of the "other" responses, 6 stated "none"; 3 referenced an internal policy; and 3 were drafting procedures. 
Comparative use of written policies and procedures suggests MAC institutions are generally on par with the ARL community. SPEC Kit 329 stated that $56 \%$ of respondents had developed ingest and processing workflows. This is nearly identical to the $57 \%$ of respondents in this survey who reported having written policies and surprisingly less than the $65 \%$ who reported written procedures. Similarly, the percentage of restriction and PII policies in place among SPEC Kit 329 respondents and MAC institutions is almost identical at 20\% and 19\% respectively. Only 9\% of SPEC Kit 325 respondents had written "digital preservation policies," lower than all but one of the policy percentages in figure $6 .{ }^{39}$

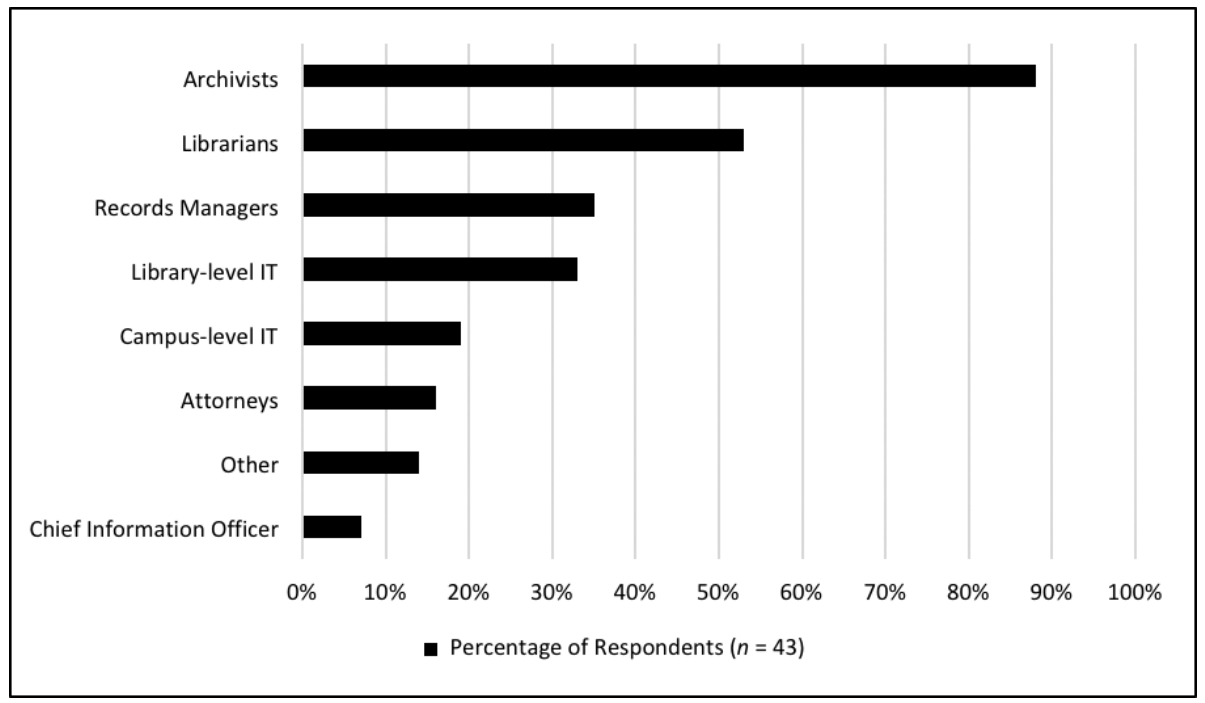

Figure 7: Stakeholders involved in developing born-digital records policies and procedures at $M A C$ institutions

Figure 7 ranks the various stakeholders developing born-digital records management policies and procedures among respondents. ${ }^{40}$ Although most reported multiple stakeholders, 21\% ( $n=9)$ selected only one listed category, all of which were either "archivists" or "librarians." Cross-disciplinary collaboration is common between this and the comparison studies. Zach and Peri (2010) found that records managers (57.9\%), CIO or data managers (61.4\%), and attorneys (68.4\%) contributed to ERM program development. The SPEC Kits also show significant collaboration in policy and program development. ${ }^{41}$

Last, most records retention schedules do not include appraisal guidelines specific to born-digital records. Of the 44 who answered this question, 14\% $(n=6)$ use such language, while $43 \%(n=19)$ do not and 20\% $(n=9)$ were unsure. The remaining 10 respondents did not have a retention schedule. Several commented that their schedules do not distinguish media or formats. Guidance on e-mail management is the exception, but its retention and disposition are determined by those of existing series. As one person noted, "There is a series for email specifically, but it directs records holders to retain/ destroy materials according to the type of record a given email is." 


\section{Acquisition, Ingest, Preservation, and Access}

A majority of MAC institutions use a combination of open source, proprietary, and homegrown tools to manage born-digital records (see figure 8). Those who only use open source tools are not limited to small institutions with presumably limited resources, as 4 of these 8 respondents have at least 20,000 students.

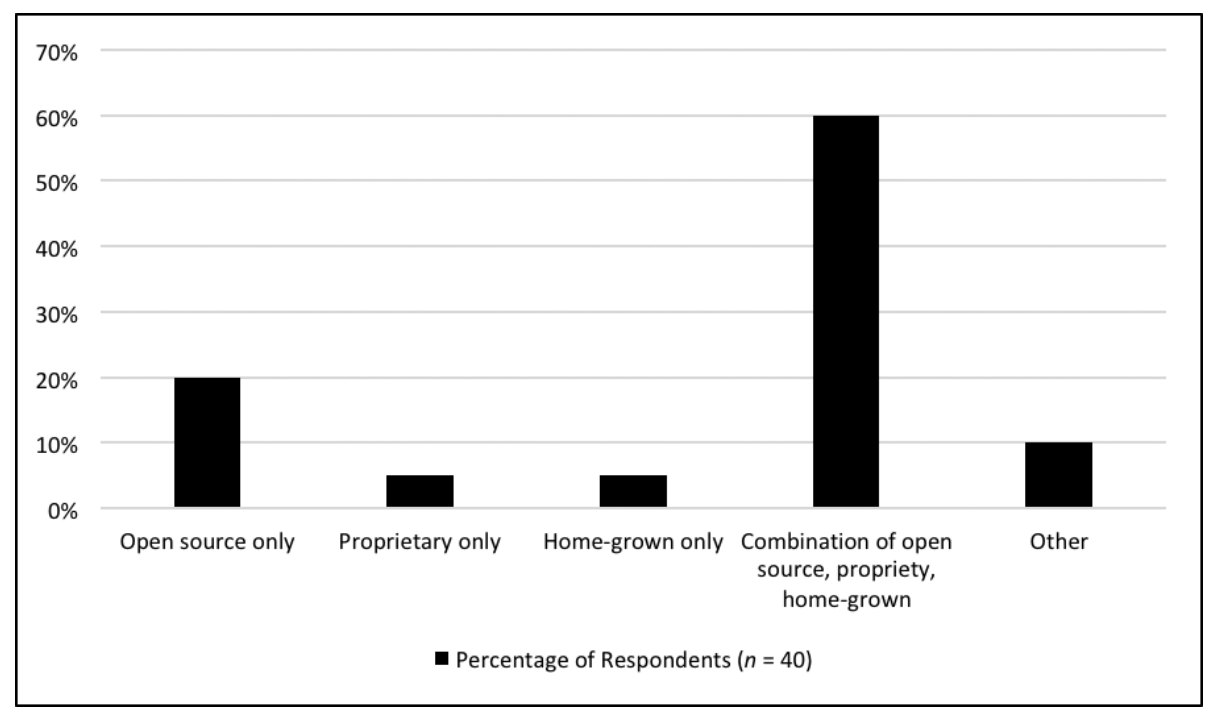

Figure 8: Types of tools used for born-digital records acquisition, processing, preservation, and access among $M A C$ institutions

Table 2: Tools and Services Used for Born-Digital Records Management

\begin{tabular}{|c|c|c|c|}
\hline Acquisition, Ingest, and Preservation $(\boldsymbol{n}=\mathbf{3 3})$ & \multicolumn{2}{|c|}{ Access $(\boldsymbol{n}=\mathbf{3 4})$} \\
\hline Tool & $\mathbf{f}$ & Tool & $\mathbf{f}$ \\
\hline BitCurator & 11 & CONTENTdm & 13 \\
\hline Archive-It & 10 & DSpace & 6 \\
\hline Archivematica & 6 & Archive-It & 5 \\
\hline Preservica & 4 & Digital Commons & 4 \\
\hline Forensic Toolkit & 3 & Homegrown System & 4 \\
\hline Data Accessioner & 3 & Islandora & 3 \\
\hline Bagger & 2 & Preservica & 3 \\
\hline Fixity & 2 & ArchivesSpace & 2 \\
\hline TeraCopy & 2 & Fedora Commons & 2 \\
\hline Homegrown System & 2 & Samvera & 2 \\
\hline
\end{tabular}




\begin{tabular}{|c|c|c|c|}
\hline \multicolumn{2}{|c|}{ Acquisition, Ingest, and Preservation ( $n=33)$} & \multicolumn{2}{|c|}{ Access $(n=34)$} \\
\hline Tool & $f$ & Tool & $f$ \\
\hline Past Perfect & 2 & Bepress & 2 \\
\hline BagIt & 2 & Omeka & 2 \\
\hline FTK Imager & 2 & Institutional Website & 2 \\
\hline DROID & 2 & WeTransfer & 1 \\
\hline ArchivesSpace & 1 & WordPress & 1 \\
\hline MetaArchive Cooperative & 1 & Flickr & 1 \\
\hline Exactly & 1 & Box & 1 \\
\hline Amazon Glacier & 1 & Rosetta & 1 \\
\hline Digital Preservation Network & 1 & Luna & 1 \\
\hline Linear Tape-Open & 1 & Internet Archive & 1 \\
\hline TreeSize Pro & 1 & Google Drive & 1 \\
\hline Samvera & 1 & YouTube & 1 \\
\hline Fedora & 1 & ResCarta & 1 \\
\hline DSpace & 1 & Extensis & 1 \\
\hline Archivists' Toolkit & 1 & & \\
\hline KryoFlux & 1 & & \\
\hline $\begin{array}{l}\text { NARA File Analyzer and } \\
\text { Metadata Harvester }\end{array}$ & 1 & & \\
\hline Karen's Directory Printer & 1 & & \\
\hline Box & 1 & & \\
\hline Rosetta & 1 & & \\
\hline $\begin{array}{l}\text { FC5025 USB 5.25” Floppy } \\
\text { Controller }\end{array}$ & 1 & & \\
\hline Disk Image and Browse & 1 & & \\
\hline $\begin{array}{l}\text { Microsoft File Checksum } \\
\text { Integrity Verifier }\end{array}$ & 1 & & \\
\hline $\begin{array}{l}\text { Data Accessioner Metadata } \\
\text { Transformer }\end{array}$ & 1 & & \\
\hline HashMyFiles & 1 & & \\
\hline Archon & 1 & & \\
\hline ImgBurn & 1 & & \\
\hline HandBreak & 1 & & \\
\hline CDex & 1 & & \\
\hline PSTViewer & 1 & & \\
\hline Quick View Plus & 1 & & \\
\hline Bepress & 1 & & \\
\hline Internet Archive & 1 & & \\
\hline Identity Finder & 1 & & \\
\hline
\end{tabular}


Table 2 displays responses to two questions for which respondents listed specific tools and services used for managing born-digital records and the frequency at which they were mentioned. Comprehensive tools such as Archivematica and Preservica were surprisingly underrepresented. Instead, format-specific Archive-IT (websites) and digital forensics-focused BitCurator were the most frequently mentioned acquisition, ingest, and preservation tools. ${ }^{42}$ Both SPEC Kit 329 and this study show similar proportional distribution across the access methods (see figure 9), though SPEC Kit 329 respondents are providing greater access to born-digital records. ${ }^{43}$

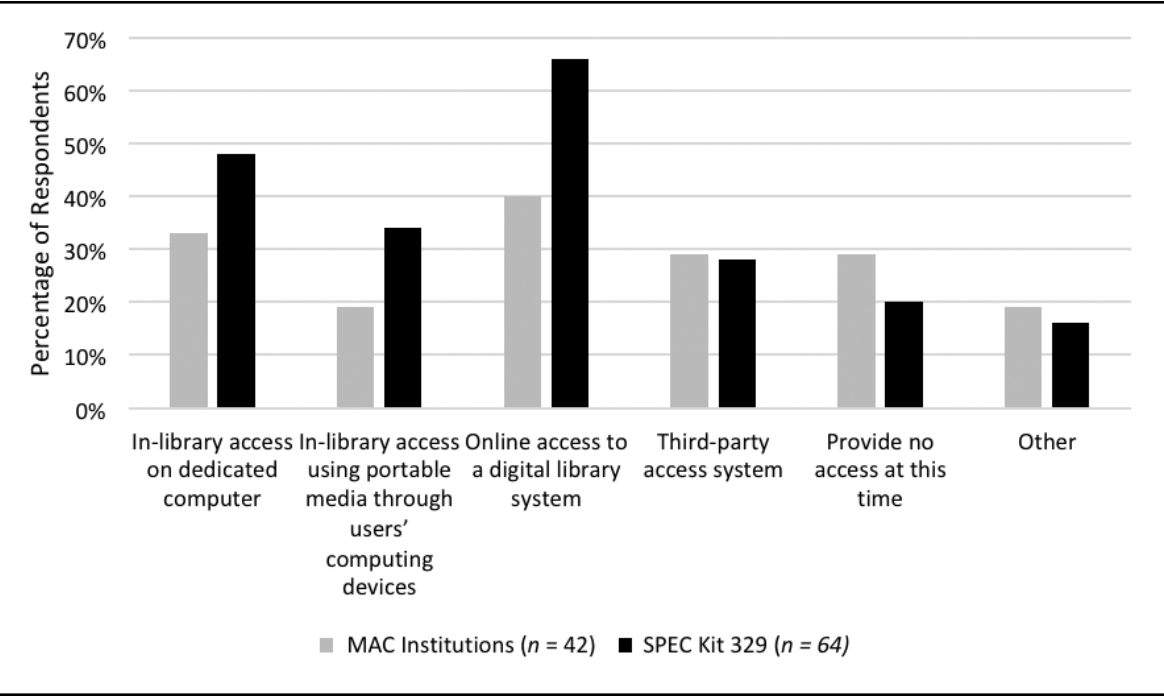

Figure 9: Access methods for born-digital records

Respondents are managing a wide range of born-digital record formats (see figure 10). Although 39\% of respondents have acquired e-mail, none specified e-mail-specific tools such as Aid4Mail or MailArchiva to manage these records. The only additional format identified in the "other" responses was PDF. Only 18\% of respondents limited or restricted file formats considered for preservation. The percentages of respondents collecting metadata at the file/item and collection levels of description are similar whether the metadata is captured via automation or created by archivists (see table 3). The only additional level of description at which metadata is created or captured noted in the "other" responses was series. Most "other" responses explained that they treat metadata strategy on a case-by-case basis or in the planning stage without a final decision. Responses expressed the same sentiment concerning types of metadata created or captured.

The data shown in table 3 lag behind the percentages reported in SPEC Kit 325. Sixtynine percent of SPEC Kit 325 respondents restricted the types of file formats accepted for preservation. These institutions also generated item-level (94\%) and collection-level (82\%) metadata at much higher rates. The same was true for the types of metadata created, specifically, administrative (100\%), technical (98\%), and structural (86\%). ${ }^{44}$ 
In the present study, the percentages for creating and capturing metadata at any level of description are surprisingly low considering that even the simplest of freely available tools automatically generate technical metadata or require that basic description be entered into data fields for the tools to function. The discrepancies between this study and SPEC Kit 325 may stem from the fact that SPEC Kits limited their surveys to wellfunded ARL institutions.

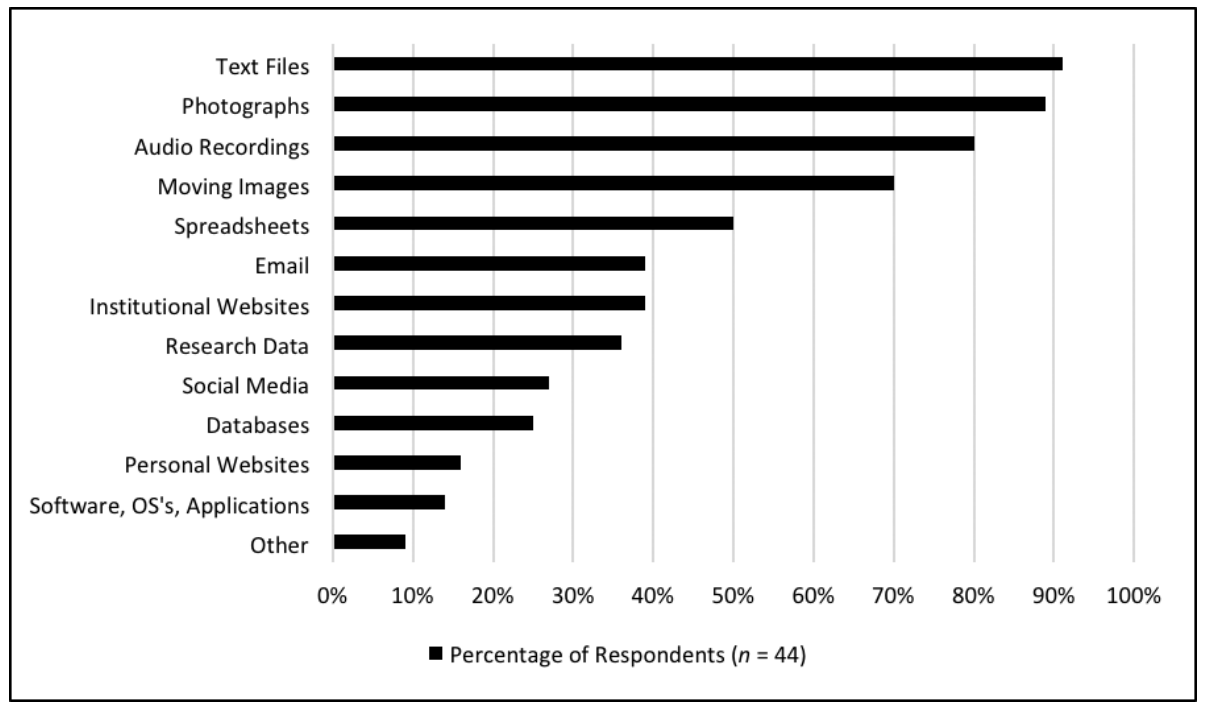

Figure 10: Types of born-digital records acquired

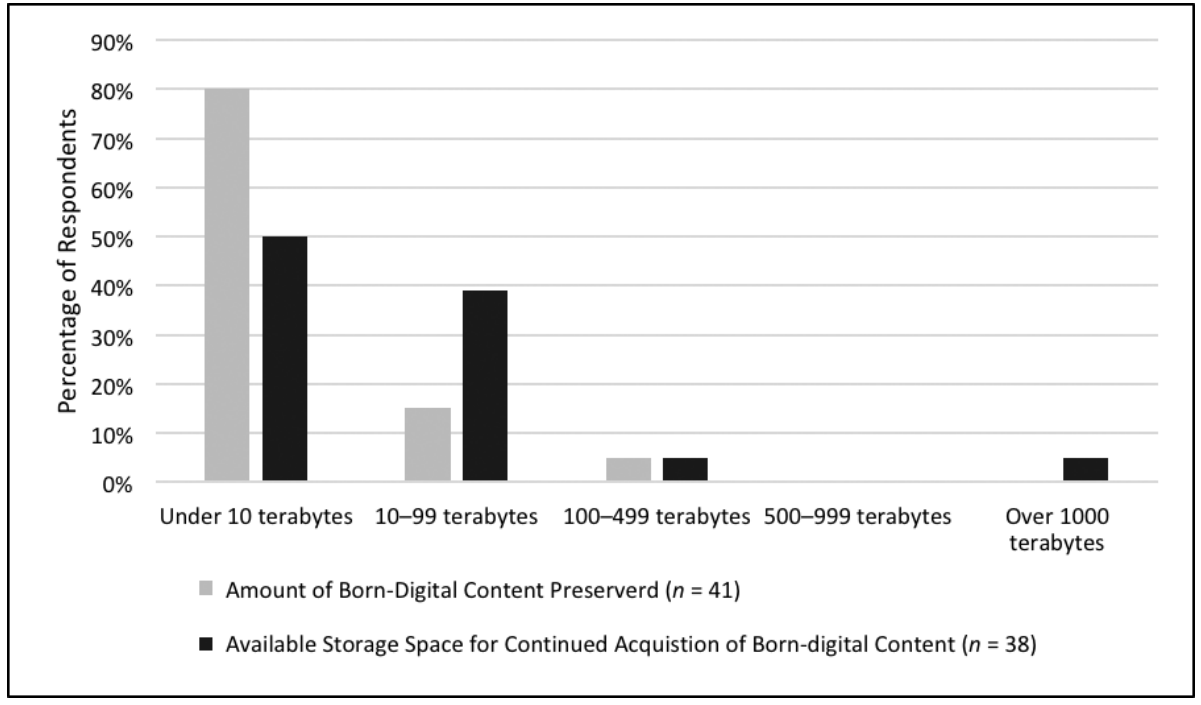

Figure 11: Amount of born-digital content preserved and available storage space for future acquisitions 
Table 3: Born-Digital Records Processing and Metadata Practices among Survey Respondents

\begin{tabular}{|c|c|c|c|}
\hline & Yes & No & Not Sure \\
\hline $\begin{array}{l}\text { Limit file formats } \\
\text { considered for preservation }\end{array}$ & $18 \%$ & $57 \%$ & $25 \%$ \\
\hline$(n=44)$ & (8) & (25) & (11) \\
\hline
\end{tabular}

\begin{tabular}{c|c|c|c|}
\cline { 2 - 4 } & File/ltem-Level & Collection-Level & Other \\
\cline { 2 - 4 } $\begin{array}{c}\text { Description level at which } \\
\text { metadata is captured during } \\
\text { acquisition, ingest, and } \\
\text { processing }\end{array}$ & $60 \%$ & & \\
$(n=35)$ & $(21)$ & $69 \%$ & $29 \%$ \\
& & $(24)$ & $(10)$ \\
\hline
\end{tabular}

\begin{tabular}{c|c|c|c|}
\cline { 2 - 4 } & File/ltem-Level & Collection-Level & Other \\
\cline { 2 - 4 } & & & \\
$\begin{array}{c}\text { Description level at which } \\
\text { metadata is created during } \\
\text { acquisition, ingest, and } \\
\text { processing }\end{array}$ & $62 \%$ & $73 \%$ & $27 \%$ \\
$\quad(n=37)$ & $(23)$ & $(27)$ & $(10)$ \\
\hline
\end{tabular}

\begin{tabular}{|c|c|c|c|c|c|}
\cline { 2 - 5 } & Administrative & Technical & Structural & Descriptive & Other \\
\cline { 2 - 6 } $\begin{array}{c}\text { Type of metadata created or } \begin{array}{c}\text { captured } \\
(n=39)\end{array} \\
74 \%\end{array}$ & $74 \%$ & $41 \%$ & $87 \%$ & $13 \%$ \\
$(29)$ & $(29)$ & $(16)$ & $(34)$ & $(5)$ \\
\hline
\end{tabular}

\section{Digital Storage}

Eighty percent of respondents reported preserving less than 10 terabytes of born-digital records (see figure 11). Of the 8 institutions preserving 10 or more terabytes, 6 had at least 20,000 students, and 5 of those were ARL members. When it comes to available storage space, $50 \%$ had less than 10 terabytes, and 39\% had 10 to 99 terabytes available for future accessions. The study showed no apparent relationship between institutional size and available storage space. The data also do not reveal how long into the future this space will be sufficient, which depends on the average storage requirements and acquisition rate of born-digital records. 
Table 4 charts various storage strategies for stages of born-digital records management. SPEC Kit 329 presented a similar table.

Table 4: Storage Methods Used during Born-Digital Records Management Activities $(n=39)$

\begin{tabular}{|c|c|c|c|c|c|c|}
\hline & Ingest & Processing & Access & Backup & Storage & $\begin{array}{c}\text { Total } \\
\text { Respondents }\end{array}$ \\
\hline $\begin{array}{l}\text { External media (CD/ } \\
\text { DVDs, tapes, etc.) }\end{array}$ & $\begin{array}{l}83 \% \\
(24) \\
\end{array}$ & $\begin{array}{l}28 \% \\
(8) \\
\end{array}$ & $\begin{array}{l}31 \% \\
(9) \\
\end{array}$ & $\begin{array}{l}41 \% \\
(12) \\
\end{array}$ & $\begin{array}{l}24 \% \\
(7) \\
\end{array}$ & 29 \\
\hline $\begin{array}{l}\text { IT-supported network } \\
\text { file system (including } \\
\text { storage area network) }\end{array}$ & $\begin{array}{l}76 \% \\
(25) \\
\end{array}$ & $\begin{array}{l}70 \% \\
(23) \\
\end{array}$ & $\begin{array}{l}61 \% \\
(20) \\
\end{array}$ & $\begin{array}{l}79 \% \\
(26) \\
\end{array}$ & $\begin{array}{l}85 \% \\
(28) \\
\end{array}$ & 33 \\
\hline $\begin{array}{l}\text { Local/Attached } \\
\text { storage (internal } \\
\text { or external drive, } \\
\text { network-attached } \\
\text { storage, etc.) }\end{array}$ & $\begin{array}{l}64 \% \\
(21) \\
\end{array}$ & $\begin{array}{l}55 \% \\
(18) \\
\end{array}$ & $\begin{array}{l}55 \% \\
(18) \\
\end{array}$ & $\begin{array}{l}67 \% \\
(22) \\
\end{array}$ & $\begin{array}{l}45 \% \\
(15) \\
\end{array}$ & 33 \\
\hline $\begin{array}{l}\text { Distributed systems } \\
\text { (LOCKSS, Digital } \\
\text { Preservation Network, } \\
\text { iRods, etc.) }\end{array}$ & $\begin{array}{l}0 \% \\
(0)\end{array}$ & $\begin{array}{l}0 \% \\
(0) \\
\end{array}$ & $\begin{array}{l}15 \% \\
(2) \\
\end{array}$ & $\begin{array}{l}100 \% \\
(13)\end{array}$ & $\begin{array}{l}62 \% \\
(8) \\
\end{array}$ & 13 \\
\hline $\begin{array}{c}\text { Cloud storage (Dura- } \\
\text { Cloud, } \\
\text { Amazon S3/Glacier, } \\
\text { Google Storage, } \\
\text { Mozy, etc.) }\end{array}$ & $\begin{array}{l}25 \% \\
(4)\end{array}$ & $\begin{array}{l}13 \% \\
(2)\end{array}$ & $\begin{array}{l}38 \% \\
(6)\end{array}$ & $\begin{array}{l}69 \% \\
(11)\end{array}$ & $\begin{array}{l}63 \% \\
(10)\end{array}$ & 16 \\
\hline
\end{tabular}

The two tables show a similar use of strategies. Both depict a logical flow from unstable media during ingest toward increasingly reliable digital environments for processing, backup, and storage. In both, network file systems prevail for access and distributed systems for backup.

However, some interesting differences exist. One would expect the use of local/attached storage for ingest to be greater than 64\%, more like the 81\% reported in SPEC Kit 329. The $67 \%$ of respondents using this strategy for backups, however, is much larger than the 40\% reported in SPEC Kit 329. Fewer SPEC Kit 329 respondents (60\%) used network file systems (NFS) for ingest than the $76 \%$ in this study. While both charts show steady dependence upon NFSs across all management activities, the $85 \%$ using them here for long-term storage far exceeds the 45\% reported in SPEC Kit 329. SPEC Kit 329 reported lower percentages of cloud storage use for backup and storage (both 33\%) than those in table 4 and, instead, use distributed systems for these functions at $76 \%$ and 
90\%, respectively. ${ }^{45}$ The ARL respondents to the present survey showed similar preference for distributed systems for these functions, representing 62\% (8 of 13) and 50\% (4 of 8) of backup and storage responses, respectively. By contrast, less than half of those using cloud storage for backup and storage functions were ARL respondents, representing $45 \%$ and $30 \%$ of total responses, respectively.

The preponderance of external media, NFSs, and local/attached storage in both surveys reflects the ubiquity and affordability of these storage options. These media have institution-wide uses beyond archival purposes and are therefore likely to be counted among routine operating expenses. In contrast, distributed and cloud services are expensive, often external services requiring additional costs and justification to resource allocators.

Figure 12 shows that of those respondents using geographically dispersed storage, more did so for preservation files alone (38\%). Slightly more than a quarter preserved both preservation and access files in this way, while slightly less than a quarter preserved neither in geographically dispersed storage, indicating that storage was either local or nonexistent, as one of the "other" comments noted.

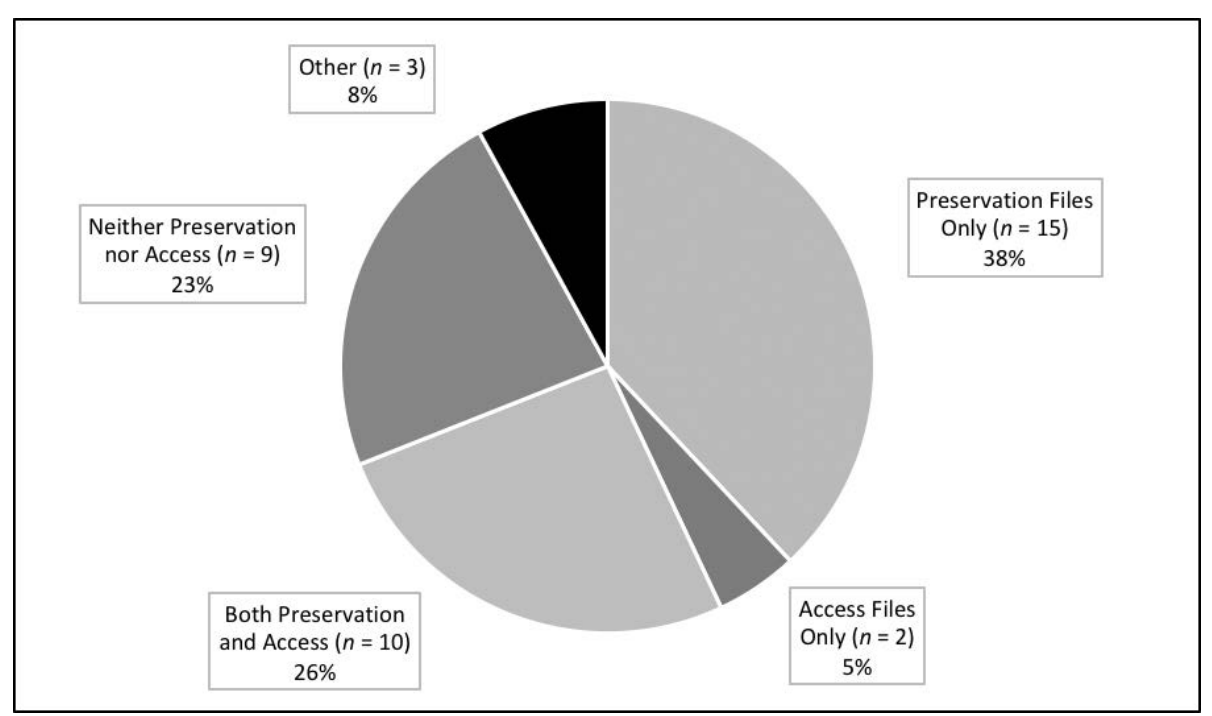

Figure 12: Use of geographically dispersed storage for preservation and access files ( $\mathrm{n}=39)$

Respondents rarely used dispersed storage for all born-digital files/collections (8\%). The majority (54\%) were selective about which materials warrant the expense of dispersed storage, while $27 \%$ stored no born-digital files/collections. Most respondents (49\%) kept 2 copies of preservation files (or AIPs), while 29\% maintained 1 copy, $14 \%$ maintained 3 copies, and 9\% maintained 4 or more copies. One commenter stated that decisions on the number of duplicative copies kept were made on a case-by-case basis: "Some digital files are backed up with more copies than others. There usually is at least one." 


\section{Sustainability}

The overwhelming majority of respondents relied upon the library operating budget to fund born-digital records preservation activities (see figure 13). Indeed, of the 39 who selected operating budget, 26 (67\%) relied solely on this funding source, while only 13 (32\%) selected an additional source. The only instance of a respondent selecting a funding source that was not paired with "library operating budget" was an "other" response that stated: "Centralized University of Missouri System library IT level provides storage costs and support. At the campus library level, the library operating budget has provided support for FTE and digital curation workstation expenses." A second "other" response identified the "university central administration budget" as an additional source, while the third "other" selection did not specify an answer. A similar question asked in SPEC Kit 325 reported higher percentages for IT budget (62\%), grants or awards (62\%), and gifts or endowments (35\%). Some respondents also drew upon the materials budget (38\%). ${ }^{46}$ The diversity of funding sources cited by ARL member respondents of SPEC Kit 325 may reflect broader institutional support from which to tap financial resources.

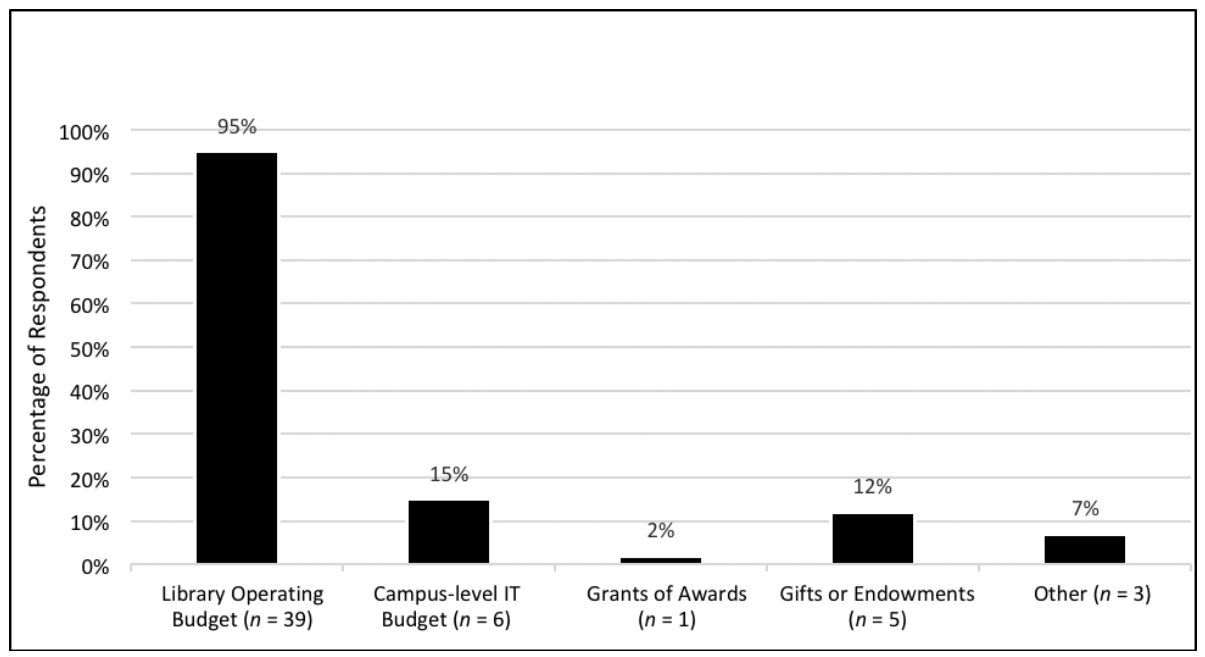

Figure 13: Funding sources supporting born-digital records preservation activities $(\mathrm{n}=41)$

Insufficient staffing and funding were the biggest challenges to developing borndigital records preservation programs (see figure 14). Even a majority of ARL member respondents identified these as significant, at $67 \%(n=10)$ and $60 \%(n=9)$ respectively. Responses for "other" that were distinguishable from the listed challenges included lack of time to explore preservation tools and best practices, lack of general planning initiatives, and lack of physical infrastructure such as digital storage capacity. Staff, funding, and expertise topped the list of challenges because new personnel and professional development depend on funding. In contrast, archives can build institutional support and coordinate among stakeholders without additional resources using existing communication channels. 
Thirty respondents described plans and strategies to address these challenges. Although often vague, the responses were categorized based on commonalities, and the percentages that follow exceed $100 \%$ because some responses fell into multiple categories. The categories included none; outreach, conversation, collaboration; personnel; tools and services; and funding. Nine (30\%) replied with some version of "no active strategies at this time" or identified budget cuts as a reason for inaction. Thirteen (43\%) noted outreach and collaborative initiatives to educate and involve stakeholders such as campus IT professionals, administrators, and archivists and librarians across university systems. Systemwide synergy helps smaller institutions access the resources of their larger sister schools. One respondent stated that new positions at larger schools allocate a percentage of job duties toward assisting smaller schools. Another respondent described a systemwide committee that has led self-assessments, inventoried digital assets, and established geographically dispersed storage. Other respondents reported drafting policies and white papers to support outreach. One archivist prioritized improving finding aids and digital collections before beginning on digital preservation outreach.

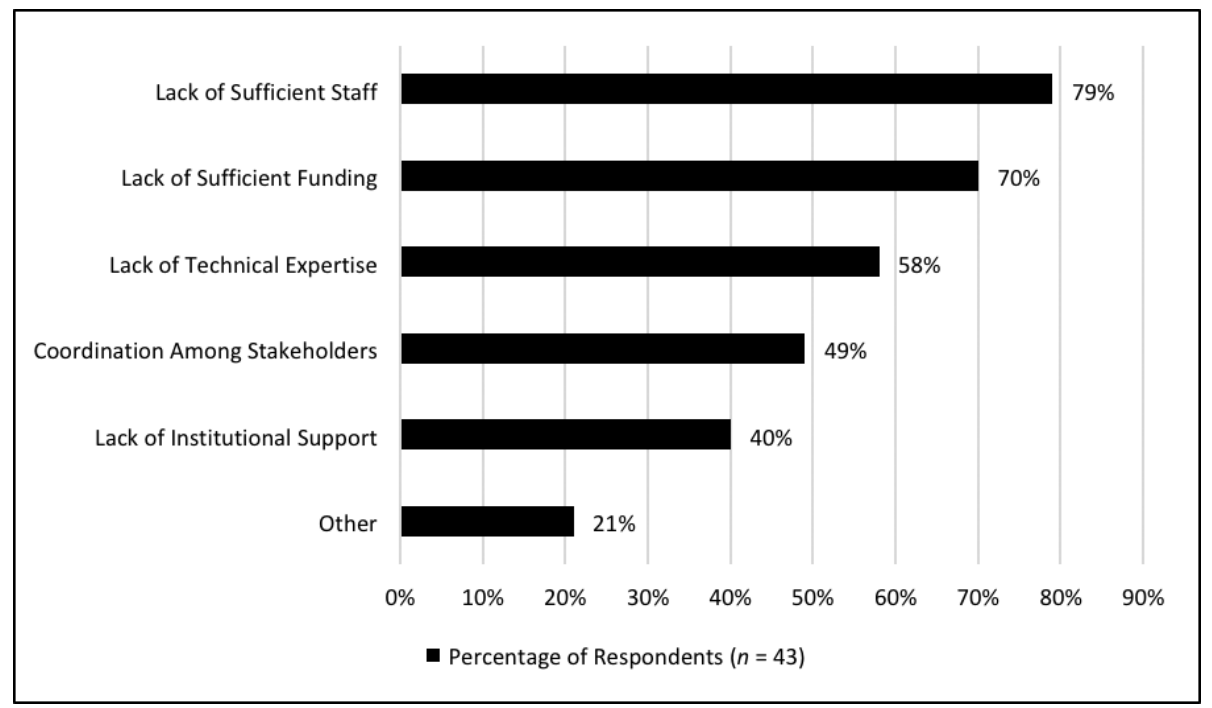

Figure 14: Challenges to born-digital records preservation

Nine respondents (30\%) are implementing "hardware and software solutions" with Preservica being the most frequently cited tool or service. Other referenced tools included CONTENTdm, Bepress, DSpace, the Internet Archive, and Archivematica, and one respondent referred to the Open Archival Information System Reference Model. Only 3 responses (10\%) were personnel-related, including hiring additional staff or retooling open positions to include digital preservation responsibilities. Fewer (2, or 7\%) identified professional development or seeking grants to support digital preservation programs. Other respondents mentioned funding as general expressions of financial need rather than specific strategies aimed at satisfying the need. It is not clear which drives the other: whether the low percentage reporting personnel, funding, and professional 
development strategies reflects the fact that staff, funding, and expertise are the top challenges to digital preservation (see figure 14), or whether the lack of strategies in these areas exacerbates said challenges. That stakeholder coordination and institutional support are the least challenging barriers to digital preservation programs may follow from the fact that outreach and collaboration represent the most common strategies.

\section{Discussion}

The present survey (2017) does not demonstrate significant advancement of born-digital preservation programs since SPEC Kit 325 (2011) and SPEC Kit 329 (2012). It shows that in some instances midwestern four-year public colleges and universities are on par with the ARL-focused SPEC Kit studies. This is particularly true for activities that do not require significant financial investment and can be accomplished with existing resources. MAC institutions are often as engaged with born-digital records as the ARL community in both planning and implementing preservation strategies. Neither group has consistently adopted language specific to born-digital records in acquisition or accessioning documents, nor instituted policies regarding PII. Both groups share a variety of stakeholders involved in digital preservation planning and implementation, a range of types of born-digital records preserved, the use of multiple tools during ingest and preservation activities, and a similar percentage of institutions implementing written policies and procedures. Both groups employ progressively stable storage solutions from acquisition to preservation management activities, though with different preferences for backup and storage strategies.

The ARL community is advanced in areas that typically require resources that smaller to midsized MAC institutions may lack. They can devote more staff to born-digital records and are better able to add positions for this purpose. The ARL community is more active in limiting file formats selected for preservation and capturing or creating administrative, technical, and structural metadata. They also provide greater access to born-digital records than MAC institutions, albeit not without challenges. Last, SPEC Kit 325 indicated that digital preservation was more likely to be supported using various funding sources as opposed to sole reliance on the library operating budget. While every archives faces the same challenges in preserving born-digital records, ARL institutions, in this survey and the SPEC Kits, are, overall, better suited to address them.

\section{Conclusion: A Model?}

Advancements in best practices, tools and services, storage technology, and continuing education opportunities have equipped a growing number of archivists with the skills needed to manage born-digital records, even if primitively, at institutions of all sizes. The percentage of institutions both in this survey and the SPEC Kit studies that are planning for or working with born-digital records-85\%, 80\%, and 92\%, respectivelyis far higher than Zach and Peri's finding that $49 \%$ were planning or implementing a formal ERM program. However, neither this survey nor the comparison studies point toward a uniform solution for born-digital records preservation. While the data 
demonstrate that archivists aim to follow best practices, resource disparities and the array of tools and services in use complicate the development of step-by-step or standardized guidance in creating and sustaining a digital preservation program, resulting in a variety of approaches. Several models offer thorough guidance and considerations for planning, implementing, and assessing a preservation program. ${ }^{47}$ However, these typically present lofty goals and ideal solutions unachievable for institutions with limited resources. Many also lack specific recommendations on tools, storage strategies, and workflows for institutions that struggle to devote staff time to researching and experimenting on their own, the Digital POWRR resources being an exception. ${ }^{48}$

A uniform solution, achievable across the spectrum of archival repositories, is unlikely to materialize. Digital preservation infrastructure and workflow depend upon available resources. A comment in this survey best captured the institution-specific nature of digital preservation programs: "Continue chipping away at the problem and experimenting with what digital preservation solutions might work best for us." Accordingly, a matrix linking reasonably achievable infrastructure and workflows with corresponding, categorized levels of financial, technical, and human resources may be more useful for resource-strapped archives seeking to develop digital preservation activities than ideal, blanket models. Anne Kenney and Nancy McGovern suggest such an approach:

The focus on [technological solutions has] reduce[d] things to on or off statuseither you have a solution or you do not. This either/or assessment gives little consideration to the effort required to reach the on stage, to a phased approach for reaching the on stage, or to differences in institutional settings. Nor does it take into account that a partial program at one institution may represent a fully mature program at another. . . Insufficient attention has been paid to the institutional context in which digital preservation programs must be developed. What emphasis exists has been placed on constructing models and frameworks . . . but these presume a fully mature program and do not address how such programs can be phased in. ${ }^{49}$

Kenney and McGovern do not recommend specific tools and infrastructure, but their emphasis on the different institutional contexts in which archivists work, as well as appropriate solutions relative to these contexts, highlights the mindset required when considering digital preservation models.

\section{ABOUT THE AUTHOR}

Matt Gorzalski has been the university archivist at Southern Illinois University Carbondale since 2012. He obtained his MLIS from the University of Pittsburgh. His research interests include arrangement and description, college and university archives, and electronic records. 


\section{NOTES}

1. Lisl Zach and Marcia Frank Peri, "Practices for College and University Electronic Records Management (ERM) Programs: Then and Now," American Archivist 73 (Spring/Summer 2010): 122.

2. Archival literature on the personal computer and electronic records is noted in Erin O'Meara and Kate Stratton, "Preserving Digital Objects," in Digital Preservation Essentials, ed. Christopher J. Prom (Chicago: Society of American Archivists, 2016), 9-10.

3. Examples include National Academy of Public Administration, The Effects of Electronic Recordkeeping on the Historical Record of the U.S. Government: A Report for the National Archives and Records Administration (Washington, DC: National Academy of Public Administration, 1989); Task Force on Archiving of Digital Information, Preserving Digital Information: Report of the Task Force on Archiving of Digital Information (Washington, DC: Commission on Preservation and Access, 1996); Meg Bellinger et al., The State of Digital Preservation: An International Perspective (Washington, DC: Council on Library and Information Resources, 2002); Margaret Hedstrom, It's About Time: Research Challenges in Digital Archiving and Long-term Preservation: Final Report (Washington, DC: Library of Congress, 2003).

4. Lisa B. Weber, Electronic Records Issues: A Report to the Commission (Washington, DC: National Archives and Records Administration, 1990); National Historical Publications and Records Commission and the Minnesota Historical Society, Research Issues in Electronic Records: Report of the Working Meeting (St. Paul: Published for the National Historical Publications and Records Commission by the Minnesota Historical Society, 1991); Minnesota Historical Society, Electronic Records Agenda Project Final Report, NHPRC 2003 Electronic Records Agenda, http://www.mnhs.org/preserve/ records/eragenda.php; Bentley Historical Library and University of Michigan School of Information, Electronic Records Research and Development: Final Report of the 1996 Conference Held at the University of Michigan, Ann Arbor, June 28-29, 1996 (Ann Arbor: University of Michigan, 1997); University of Pittsburgh, Council on Library Resources, and National Association of Government Archives and Records Administrators, Archival Administration in the Electronic Information Age: An Advanced Institute for Government Archivists, June 3-15, 1990 (Pittsburgh: School of Library and Information Science, 1990), http://files.eric.ed.gov/fulltext/ED331470.pdf; University of Pittsburgh, Council on Library Resources, and National Association of Government Archives and Records Administrators, Archival Administration in the Electronic Information Age: An Advanced Institute for Government Archivists, June 2-14, 1991 (Pittsburgh: School of Library and Information Science, 1991), http://files.eric .ed.gov/fulltext/ED344597.pdf; David Olson, “'Camp Pitt' and the Continuing Education of Government Archivists: 1989-1996," American Archivist 60, no. 2 (1997): 202-14; Wendy Duff, "Ensuring the Preservation of Reliable Evidence: A Research Project Funded by the NHPRC," Archivaria 42 (1996): 28-45; School of Information Sciences, "Functional Requirements for Evidence in Recordkeeping," University of Pittsburgh, http://www.archimuse.com/papers/nhprc/. See also National Forum on Archival Continuing Education, Final Report (Albany: Council of State Historical Records Coordinators, 2002); Council of State Archivists, "State Electronic Records Initiative," https://www.statearchivists.org/programs/state-electronic-records-initiative.

5. Luciana Duranti and Heather MacNeil, "The Protection of the Integrity of Electronic Records: An Overview of the UBC-MAS Research Project," Archivaria 42 (1996): 46-67; Heather MacNeil, "Providing Ground for Trust: Developing Conceptual Requirements for the Long-term Preservation of Authentic Electronic Records," Archivaria 50 (2000): 52-78; Heather MacNeil, "Providing Grounds for Trust II: The Findings of the Authenticity Task Force of InterPARES," Archivaria 54 (Fall 2002): 24-58; Luciana Duranti, "The InterPARES 2 Project (2002-2007): An Overview," Archivaria 64 (Fall 2007): 113-21. For a comprehensive report of "the UBC project," see Luciana Duranti, Terry Eastwood, and Heather MacNeil, Preservation of the Integrity of Electronic Records (Dordrecht, the Neth.: Kluwer Academic Publishers, 2002).

6. Examples include William Cunliffe and Michael Miller, "Writing a General Records Schedule for Electronic Records," American Archivist 52 (Summer 1989): 350-56; David A. Wallace, "Metadata and the Archival Management of Electronic Records: A Review," Archivaria 36 (Autumn 1993): 87-110; Margaret Hedstrom, "Descriptive Practices for Electronic Records: Deciding What Is Essential and Imagining What Is Possible," Archivaria 36 (Autumn 1993): 53-63; Margaret Hedstrom, "How Do Archivists Make Electronic Archives Usable and Accessible?," Archives and Manuscripts 
26, no. 1 (1998): 6-22; Candace Loewen, "The Control of Electronic Records Having Archival Value," Archivaria 36 (Autumn 1993): 64-73; Philip C. Bantin, "Strategies for Managing Electronic Records: A New Archival Paradigm? An Affirmation of Our Archival Traditions?," Archival Issues 21, no. 1 (1998): 17-34; Duranti, "The Protection of the Integrity of Electronic Records," 46-67; Bethany Anderson, Fynnette Eaton, and Scott W. Schwartz, "Archival Appraisal and the Digital Record: Applying Past Tradition for Future Practice," New Review of Information Networking 20, nos. 1-2 (2015): 3-15; Jacques Grimard, "Managing the Long-term Preservation of Electronic Archives or Preserving the Medium and the Message," Archivaria 59 (Spring 2005): 153-67; Richard Fyffe, Deborah Ludwig, and Beth Forrest Warner, "Digital Preservation: A Campus-wide Perspective," ECAR Research Bulletin 18 (2005): 1-10; Micah Altman et al., "Digital Preservation through Archival Collaboration: The Data Preservation Alliance for the Social Sciences," American Archivist 72 (Spring/Summer 2009): 170-84; Adrian Cunningham, "Good Digital Records Don't Just 'Happen': Embedding Digital Recordkeeping as an Organic Component of Business Processes and Systems," Archivaria 71 (Spring 2011): 21-34; Christopher A. Lee and Helen Tibbo, "Where's the Archivist in Digital Curation? Exploring the Possibilities through a Matrix of Knowledge and Skills," Archivaria 72 (Fall 2011): 123-68; Committee on Future Career Opportunities and Educational Requirements for Digital Curation, Board on Research Data and Information, Policy and Global Affairs, National Research Council of the National Academies, Preparing the Workforce for Digital Curation (Washington, DC: The National Academies Press, 2015); Wendy Duff et al., "Digital Preservation Education: Educating or Networking?," American Archivist 69 (Spring/Summer 2006): 188-212; Henry M. Gladney, "Long-term Preservation of Digital Records: Trustworthy Digital Objects," American Archivist 72 (Fall/Winter 2009): 401-35; Maria Guercio, "Principles, Methods, and Instruments for the Creation, Preservation, and Use of Archival Records in the Digital Environment," American Archivist 64 (Fall/Winter 2001): 238-69; Bruce W. Dearstyne, ed., Effective Approaches for Managing Electronic Records and Archives (Lanham, MD: Scarecrow Press, Inc., 2002); Bruce I. Ambacher, ed., Thirty Years of Electronic Records (Lanham, MD: The Scarecrow Press, Inc., 2003); Luciana Duranti, "From Digital Diplomatics to Digital Records Forensics," Archivaria 68 (Fall 2009): 39-66; Jackie Dooley, The Archival Advantage: Integrating Archival Expertise into Management of Born-digital Library Materials (Dublin, Ohio: OCLC Research, 2015), http:// www.oclc.org/content/dam/research/publications/2015/oclcresearch-archival-advantage-2015.pdf; George J. Soete, Preserving Digital Information, SPEC Kit 228 (Washington, DC: Association of Research Libraries, 1997).

7. Philip C. Bantin, "Developing a Strategy for Managing Electronic Records-The Findings of the Indiana University Electronic Records Project," American Archivist 61 (Fall 1998): 328-64; Philip C. Bantin, "The Indiana University Electronic Records Project Revisited," American Archivist 62 (Spring 1999): 153-63.

8. Amanda Kay Rinehart, Patrice-Andre Prud'homme, and Andrew Reid Huot, "Overwhelmed to Action: Digital Preservation Challenges at the Under-resourced Institution," OCLC Systems E Services 30, no. 1 (2014): 28-42; Meg Miner, "Case 16—Digital Preservation Strategies for a Small Private College," Society of American Archivists, "Campus Case Studies," http://files.archivists. org/pubs/CampusCaseStudies/CASE-16-MegMiner-Final.pdf.

9. Lisa M. Schmidt, "Preserving the H-Net Email Lists: A Case Study in Trusted Digital Repository Assessment," American Archivist 74 (Spring/Summer 2011): 257-96; Laura Carroll et al., "A Comprehensive Approach to Born-Digital Archives," Archivaria 72 (2011): 61-92; Michael Forstrom, "Managing Electronic Records in Manuscript Collections: A Case Study from the Beinecke Rare Book and Manuscript Library," American Arcbivist 72 (Fall/Winter 2009): 460-77; Joseph A. Williams and Elizabeth M. Berilla, "Minutes, Migration, and Migraines: Establishing a Digital Archives at a Small Institution," American Archivist 78, no. 1 (Spring/ Summer 2015): 84-95; Alexandra Dolan-Mescal et al., "A Digital File Inventory of the Queens College Special Collections and Archives: Findings, Analysis, and Recommendations for Longterm Preservation," OCLC Systems \& Services 30, no. 2 (2014): 78-90; Society of American Archivists, "Campus Case Studies," last modified September 12, 2017, https://www2.archivists .org/publications/epubs/Campus-Case-Studies.

10. Examples include Christopher J. Prom, ed., Digital Preservation Essentials (Chicago: Society of American Archivists, 2016); Steve Marks, Becoming a Trusted Digital Repository, ed. Michael Shallcross (Chicago: Society of American Archivists, 2015); Gabriela Redwine et al., Born Digital: 
Guidance for Donors, Dealers, and Archival Repositories (Washington, DC: Council on Library and Information Resources, 2013), https://www.clir.org/wp-content/uploads/sites/6/pub159.pdf; OCLC Research, "Demystifying Born Digital," http://www.oclc.org/research/themes/research-collections/ borndigital.html; Charles M. Dollar, Authentic Electronic Records: Strategies for Long-term Access (Chicago: Cohasset Associates, Inc., 2002); Gregory S. Hunter, Preserving Digital Information: A How-To-Do-It Manual (New York: Neal-Schuman Publishers, Inc., 2000); Robert F Smallwood, Managing Electronic Records: Methods, Best Practices, and Technologies (Hoboken, NJ: John Wiley \& Sons, 2013).

11. Victoria Irons Walch, ed., "A*CENSUS," American Archivist 69 (Fall/Winter 2006): 337, 341; Jackie M. Dooley and Katherine Luce, Taking Our Pulse: The OCLC Research Survey of Special Collections and Archives (Dublin, Ohio: OCLC Research, 2010), 25, 68. Note that page 59 of Taking Our Pulse states that $79 \%$ of respondents reported working with born-digital records in some capacity, seemingly contradicting the $35 \%$ reported on page 25 . The authors explain this discrepancy on page 26 , stating that the $35 \%$ more likely represents archivists actively working with electronic records versus the $79 \%$ who more likely have simply collected but are not necessarily actively managing born-digital records.

12. Margaret Hedstrom and Sheon Montgomery, "Digital Preservation Needs and Requirements in RLG Member Institutions," Research Libraries Group, https:/www.oclc.org/content/dam/research/ activities/digpresneeds/digpres.pdf.

13. Anne R. Kenney and Deirdre C. Stam, The State of Preservation Programs in American College and Research Libraries: Building a Common Understanding and Action Agenda (Washington, DC: Council on Library and Information Resources, 2002), 4; Mary Kandiuk, Aaron Lupton, and Catherine Davidson, Digital Image Collections and Services, SPEC Kit 335 (Washington, DC: Association of Research Libraries, 2013).

14. Bessie Schina and Garron Wells, "University Archives and Records Programs in the United Stated and Canada," Archival Issues 27, no. 1 (2002): 35-52.

15. Zach and Peri, "Practices for College and University Electronic Records Management (ERM) Programs,” 114.

16. Gail McMillan, Matt Schultz, and Katherine Skinner, Digital Preservation, SPEC Kit 325 (Washington, DC: Association of Research Libraries, 2011), 9-11. SPEC Kits are surveys published by the Association of Research Libraries on current policies and practices among member institutions.

17. Naomi L. Nelson et al., Managing Born-Digital Special Collections and Archival Materials, SPEC Kit 329 (Washington, DC: Association of Research Libraries, 2012), 11.

18. Michèle V. Cloonan and Shelby Sanett, "Preservation Strategies for Electronic Records: Where We Are Now-Obliquity and Squint?," American Archivist 65 (Spring/Summer 2002): 93. For a thorough cost and economic argument for digital preservation, authored eight years later, see Blue Ribbon Task Force on Sustainable Digital Preservation and Access, "Sustainable Economics for a Digital Planet: Ensuring Long-term Access to Digital Information” (February 2010), http://brtf.sdsc.edu/biblio/BRTF_Final_Report.pdf.

19. OCLC/RLG PREMIS Working Group, "Implementing Preservation Repositories for Digital Materials: Current Practice and Emerging Trends in the Cultural Heritage Community," http://www.oclc.org/content/dam/research/activities/pmwg/surveyreport.pdf.

20. Elizabeth Yakel et al., "Institutional Repositories and the Institutional Repository: College and University Archives and Special Collections in an Era of Change," American Archivist 71 (Fall/ Winter 2008): 328, 339-41.

21. Susan E. Davis, "Electronic Records Planning in 'Collecting' Repositories," American Archivist 71 (Spring/Summer 2008): 185.

22. Micah Altman et al., "NDSA Storage Report: Reflections on National Digital Stewardship Alliance Member Approaches to Preservation Storage Technologies," D-Lib Magazine 19, nos. 5-6 (2013), doi:10.1045/may2013-altman; Michelle Gallinger et al., "Trends in Digital Preservation Capacity and Practice: Results from the 2nd Bi-annual National Digital Stewardship Alliance Storage Survey," D-Lib Magazine 23, nos. 7-8 (2017), https://doi.org/10.1045/july2017-gallinger. 
23. Daniel Noonan and Tamar Chute, "Data Curation and the University Archives," American Archivist 77 (Spring/Summer 2014): 201-40; Cynthia Hudson-Vitale et al., Data Curation, SPEC Kit 354 (Washington, DC: Association of Research Libraries, 2017); Jefferson Bailey et al., "Web Archiving in the United States: A 2016 Survey," http://ndsa.org/documents/WebArchivingintheUnitedStates_A2016Survey.pdf; Winston Atkins et al., "Staffing for Effective Digital Preservation 2017: An NDSA Report," http://ndsa.org/documents/Report_2017DigitalPreservationStaffingSurvey. pdf.

24. Jen Fifield, “Many Northeast, Midwest States Face Shrinking Workforce," May 27, 2016, http://www.pewtrusts.org/en/research-and-analysis/blogs/stateline/2016/05/27/many-northeastmidwest-states-face-shrinking-workforce; Tim Anderson, "For Midwest, Population Growth Will Be a Greater Demographic, Policy Challenge in Years Ahead," Stateline Midwest 25, no. 6 (2016): 4, http://www.csgmidwest.org/policyresearch/documents/0616-slmw.pdf.

25. Marwa Eltagouri, "Illinois Loses More Residents in 2016 than Any Other State," Chicago Tribune, December 21, 2016, http://www.chicagotribune.com/news/local/breaking/ct-illinois-populationdecline-met-20161220-story.html; Editorial Board, "Goodbye, Illinois: Residents Are Leaving for Other States," Chicago Tribune, January 6, 2015, http://www.chicagotribune.com/news/opinion/ editorials/ct-illinois-census-brookings-edit-0107-20150106-story.html; Katie Lobosco, "Illinois Is Starving State Colleges and Universities," CNN Money, June 29, 2017, http://money.cnn .com/2017/06/29/pf/college/illinois-budget-higher-education/index.html.

26. Southern Illinois University, "Financial Sustainability Plan," July 2017, http://chancellor.siu. edu/_common/doc/budget/financial-sustainability-plan-7-11-17.pdf.

27. Some examples include Valerie Strauss, "Gov. Scott Walker Savages Wisconsin Public Education in New Budget," Washington Post, July 13, 2015, https://www.washingtonpost.com/news/answer-sheet/ wp/2015/07/13/gov-scott-walker-savages-wisconsin-public-education-in-new-budget/?utm_term=. e694755fbf4b; Joe Sonka, "Kentucky's Higher Education Budget Cuts Remain among Highest in the Country," Insider Louisville, May 19, 2016, https://insiderlouisville.com/metro/educationcommunity/kentucky-higher-ed-budget-cuts-among-highest/; Jonathan Oosting, "Michigan Universities Take Hit in Budget Deal," The Detroit News, May 26, 2016, http://www.detroitnews. com/story/news/politics/2016/05/26/michigan-universities-take-hit-budget-deal/84999840/.

28. For example, Wikipedia, "List of colleges and universities in Illinois," https://en.wikipedia.org/ wiki/List_of_colleges_and_universities_in_Illinois.

29. The enrollment categories were taken from the National Center of Education Statistics Integrated Postsecondary Education Data System. Integrated Postsecondary Education Data System, "Frequently used/Derived variables, Institutions, Institution size category," https://nces.ed.gov/ipeds/ datacenter/SelectVariables.aspx?stepId=1.

30. McMillan, Schultz, and Skinner, Digital Preservation, 17; Nelson et al., Managing Born-Digital Special Collections and Archival Materials, 22; Zach and Peri, "Practices for College and University Electronic Records Management (ERM) Programs,” 114.

31. Zach and Peri, "Practices for College and University Electronic Records Management (ERM) Programs," 115. Zach and Peri's study placed more emphasis on records management than this survey did, but they emphasized records management's role in selecting born-digital records for transfer to archives.

32. Zach and Peri, "Practices for College and University Electronic Records Management (ERM) Programs," 116; McMillan, Schultz, and Skinner, Digital Preservation, 12, 65-66; Nelson et al., Managing Born-Digital Special Collections and Archival Materials, 11, 22-26.

33. Respondents were expected to provide numerical data in both the FTE and individuals categories for this question (Q8). Incomplete responses where only one data point was provided were discarded. Responses where the concept of FTE was misunderstood were also discarded. Some entered total work hours rather than the number of FTEs. For example, one respondent noted 80 FTEs and 2 individuals, suggesting they understood FTE to mean 80 hours worked by 240 -hours-per-week employees, rather than 2 FTEs and 2 individuals. Text responses were also discarded. In one case, a respondent listed 7 position titles under "individuals" rather than entering the number 7 . Collectively, these types of responses were discarded so that the usable data reflected the question's intent and to avoid introducing bias when the author was left to assume what respondents meant. 
34. McMillan, Schultz, and Skinner, Digital Preservation, 29; Nelson et al., Managing Born-Digital Special Collections and Archival Materials, 22.

35. McMillan, Schultz, and Skinner, Digital Preservation, 12.

36. While 4 respondents stated they felt sufficiently staffed, only 3 FTE values are listed because one of these respondents did not answer the FTEs and individuals question as intended (Q8), and the answer was treated as null.

37. McMillan, Schultz, and Skinner, Digital Preservation, 37-39; Nelson et al., Managing Born-Digital Special Collections and Archival Materials, 25.

38. Nelson et al., Managing Born-Digital Special Collections and Archival Materials, 30.

39. McMillan, Schultz, and Skinner, Digital Preservation, 19; Nelson et al., Managing Born-Digital Special Collections and Archival Materials, 32, 38.

40. The "other" responses included library administrators, Research Data Service staff, Campus Compliance Committee, and "none."

41. Zach and Peri, "Practices for College and University Electronic Records Management (ERM) Programs," 116; McMillan, Schultz, and Skinner, Digital Preservation, 20-29; Nelson et al., Managing Born-Digital Special Collections and Archival Materials, 22-25, 48-54.

42. Other access methods included "mediated access to materials in our 'dark archive" and "e-mail file attachments."

43. Nelson et al., Managing Born-Digital Special Collections and Archival Materials, 71.

44. McMillan, Schultz, and Skinner, Digital Preservation, 60, 67.

45. Nelson et al., Managing Born-Digital Special Collections and Archival Materials, 55.

46. McMillan, Schultz, and Skinner, Digital Preservation, 32.

47. Some include the Consultative Committee for Space Data Systems, "Reference Model for an Open Archival Information System (OAIS)," https://public.ccsds.org/Pubs/650x0m2.pdf; AIMS Working Group, "AIMS Born-Digital Collections: An Inter-Institutional Model for Stewardship," January 2012, https://dcs.library.virginia.edu/files/2013/02/AIMS_final_text.pdf; Charles Dollar and Lori Ashley, “Digital Preservation Capability Maturity Model (DPCMM),” July 6, 2015, https://tinyurl .com/ybdrfmn8; Center for Research Libraries, "Digital Preservation Metrics," 2018, https://www .crl.edu/archiving-preservation/digital-archives/metrics.

48. Digital POWRR, http://digitalpowrr.niu.edu.

49. Anne R. Kenney and Nancy Y. McGovern, "The Five Organizational Stages of Digital Preservation," in Digital Libraries: A Vision for the 21st Century: A Festschrift in Honor of Wendy Lougee on the Occasion of Her Departure from the University of Michigan, ed. Patricia Hodges and Wendy Pradt Lougee (Ann Arbor: Scholarly Pub. Office, the University of Michigan University Library, 2003), 124-25. 